\title{
Paying attention to facial cosmetic units in dermatologic surgery pays back
}

Dermatolojik cerrahide yüzün kozmetik ünitelerini dikkate almak yüz güldürür

\section{Leyla Huseynova, ๑ Gonca Elçin}

Hacettepe University Faculty of Medicine, Department of Dermatology and Venerology, Ankara, Turkey

1-What are the most important objectives in facial surgery?

Irrespective of the reason of facial surgery, whether it is for cosmetic, reconstructive, traumatic, oncologic reasons or for the repair of congenital defects, patient's satisfaction and quality of life, relies exclusively on the "normal" appearance of the face after surgery ${ }^{1,2}$. Symmetry, absence of tissue loss or tissue excess, functionality, preserved topographic consistency and the final appearance of the scar are the most important factors defining the concept of "normal" appearance and beauty of face after surgery ${ }^{2,3}$.

2-How can we optimize the outcomes of facial dermatologic surgery?

Using appropriate suture techniques and materials for the topographic site while repairing surgical wounds, optimizing the appearance of the final scar by placing suture lines along skin tension lines, applying proper surgical wound care and postoperative scar care, avoiding the distortion of the free edges such as the eyelids, lips and alar rim are crucial in obtaining desirable cosmetic results for facial dermatologic surgery ${ }^{4}$. It is also very important to consider the concept of facial cosmetic units while repairing skin defects with flaps or grafts ${ }^{5}$.

\section{3-What is a facial cosmetic unit?}

Cosmetic units also named as aesthetic units of the face are primary structural areas of the face that are separated by natural folds and borders such as the nasolabial fold,

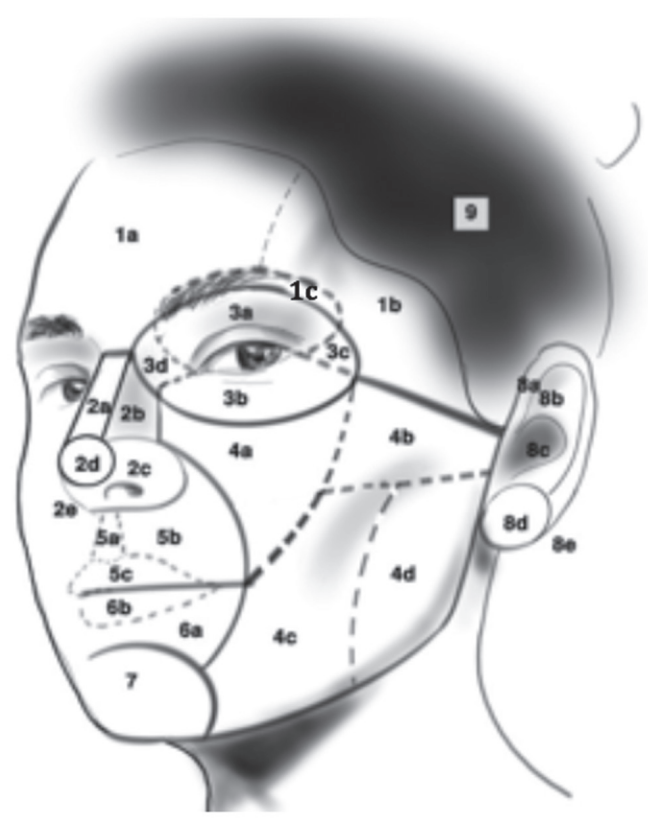

Figure 1. Facial cosmetic units and subunits. 1- Forehead, a) central, b) lateral, c) brow; 2- nose, a) dorsum, b) lateral wall, c) ala, d) tip, e) columella; 3- eyelid, a) superior, b) inferior, c) lateral canthus, d) medial canthus; 4- cheek, a) infraorbital, b) zygomatic, c) buccal, d) parotid-masseteric; 5- upper lip, a) philtrum, b) lateral, c) vermilion; 6- lower lip, a) central, b) vermilion, 7- chin; 8- ear, a) helix, b) antihelix, c) concha, d) earlobe, e) retroauricular; 9- scalp

Address for Correspondence/Yazışma Adresi: Leyla Huseynova MD, Hacettepe University Faculty of Medicine, Department of Dermatology and Venerology, Ankara, Turkey Phone: +90 5078086764 E-mail: leyla.huseynova@ymail.com Received/Geliş Tarihi: 02.12.2019 Accepted/Kabul Tarihi: 16.12.2019 ORCID: orcid.org/0000-0003-3562-1491 


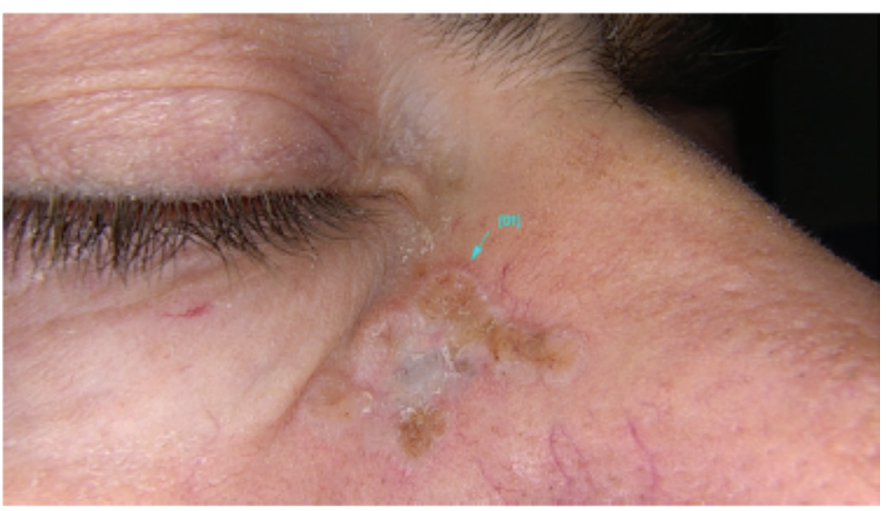

Figure 2. Basal cell carcinoma located on the right side of the face at the conjunction of three cosmetic units and subunits: the inferior eyelid (3b), the infraorbital cheek (4a) and the lateral wall of the nose (2b)

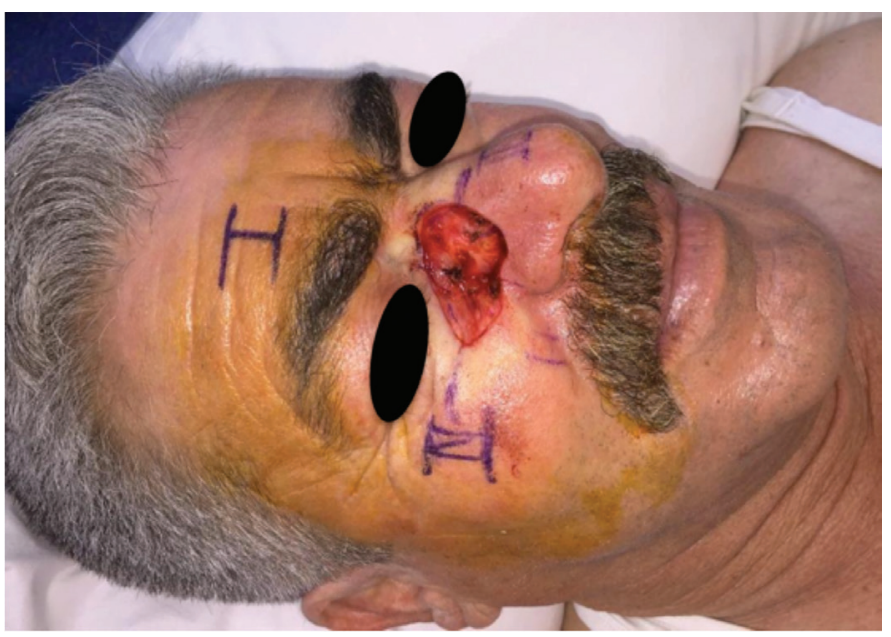

Figure 3. Final surgical wound at the junction of the eyelid, nose and cheek cosmetic units with a diameter of $35 \times 30 \mathrm{~mm}$

mental crease, vermilion border, eyebrow and hair-line. These units are composed of skin with relatively similar histology, thickness, color, texture, solar exposure, hair distribution and sebaceous features. Quantity and mobility of subcutaneous tissue within the same facial cosmetic units are moderately equal ${ }^{6}$. Although it is difficult to visually distinguish these units on young face, the perceptible division of cosmetic units becomes more apparent with increasing age ${ }^{7}$.

\section{4-How many cosmetic units do we have on the face?}

The major facial cosmetic units are the forehead, nose, eyelids, cheeks, upper and lower lips, chin, ears and the scalp ${ }^{6}$. Because of anatomic complexity and with the aim of further refining cosmetic outcomes of reconstruction, main cosmetic units are in turn subdivided into various subunits (Figure 1)

\section{5-What is the importance of facial cosmetic units in dermatologic surgery?}

For optimal cosmetic outcomes, incisions and suture lines must be placed along cosmetic unit junctions without crossing them. By this, surgical margins are hidden within natural borders, allowing scars to be imperceptible ${ }^{4}$. It is also very important to designate flaps within the limits of each cosmetic unit where the primary defect is, as it

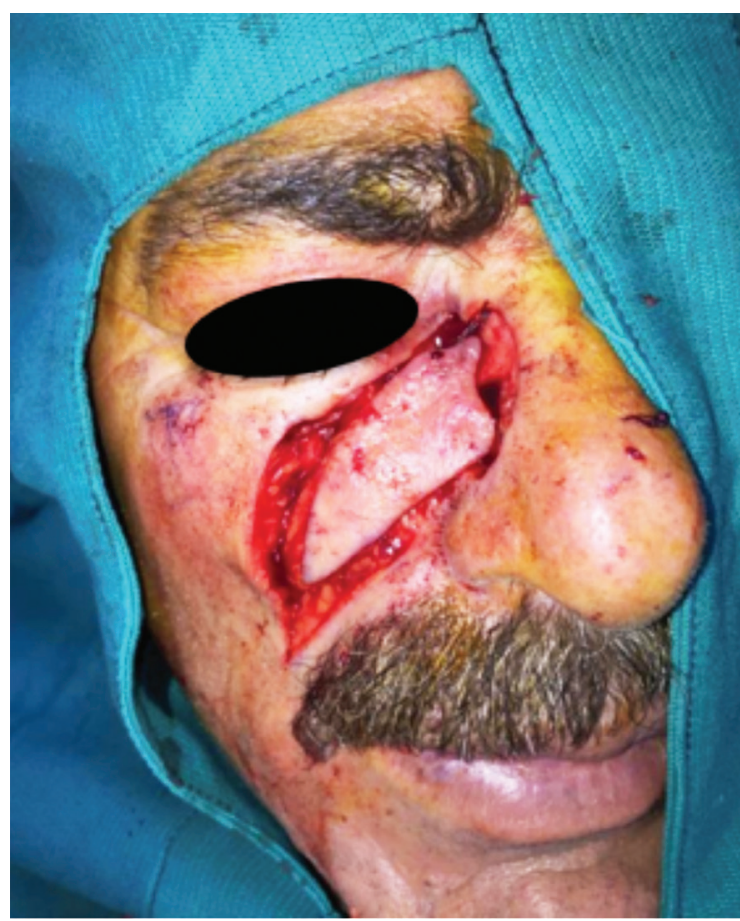

Figure 5. As seen in the picture, the whole surgical defect could have been restored fully with the island pedicle flap taken from the cheek. It would be an easy and less time-consuming procedure. However, repairing the nose unit with a flap from the cheek unit would have caused a bumpy scar and distortion of the normal anatomic appearance

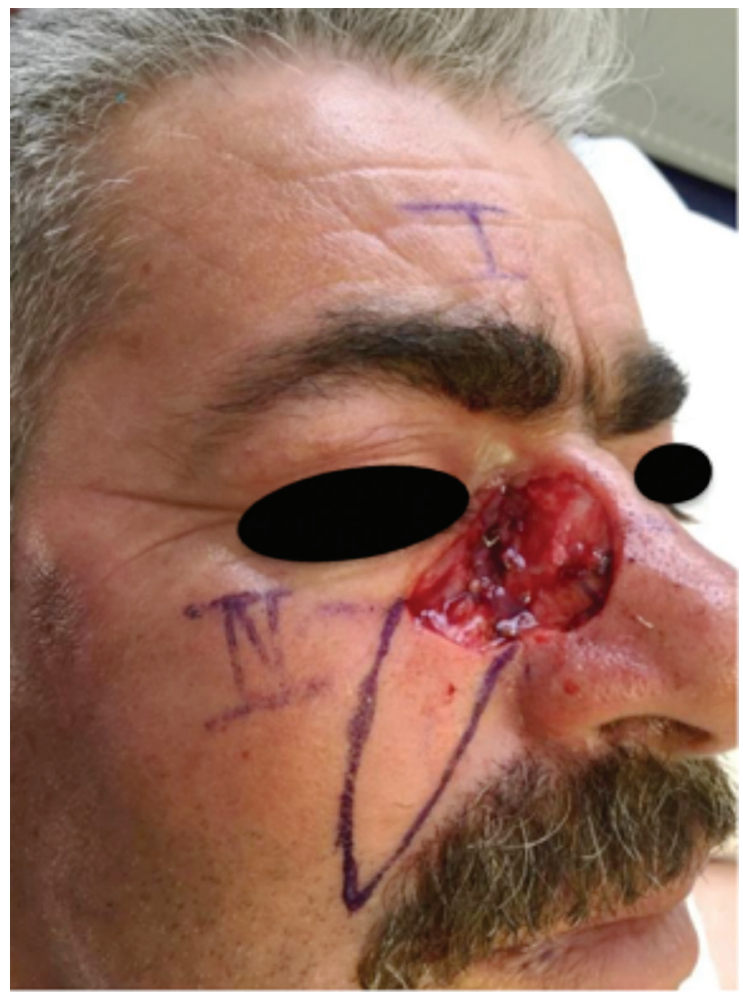

Figure 4. Outlined restoration plan of the surgical defect with an island pedicle flap. In order to optimize the final appearance of scar, incision lines were placed within the nasolabial fold and along the skin tension lines 


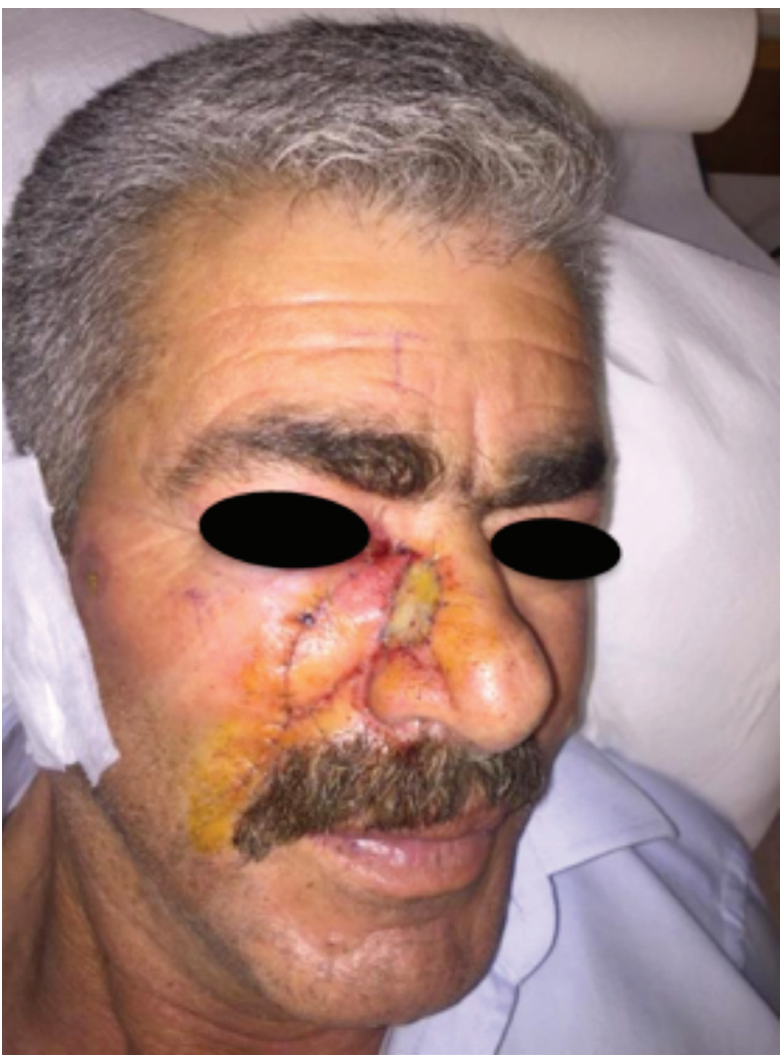

Figure 6. A combination of an island pedicle flap from the cheek to restore the cheek unit together with a full thickness skin graft harvested from the parotid-masseteric cheek to restore the lateral wall of the nose unit was used to close this defect. Graft donor site is covered with dressing
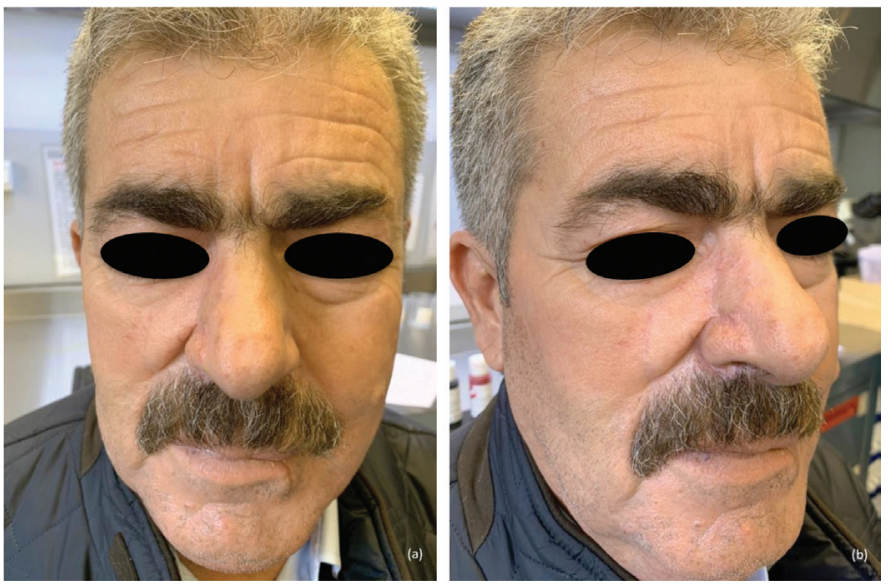

Figure 7. a) Frontal and b) oblique views 7 months postoperatively demonstrate excellent cosmetic result. Note the well-camouflaged, inconspicuous scars along borders of cosmetic eyelid, nose and cheek units. Normal anatomic features are well-preserved enables the homogenous distribution of skin thickness, color and texture along surgical site ${ }^{2}$. Repair of the complete cosmetic unit is also recommended, even in the cases of partial involvement of the unit. Although it is much more easy and time-saving to restore defects affecting various cosmetic units with one flap, these lesions should be reconstructed by considering each individual unit ${ }^{5}$.

Herein, we present a 57-year-old man who was admitted to our clinic with a pink to brown colored lesion with irregular elevated borders located on his right cheek for 3 years (Figure 2). Punch biopsy taken from the lesion was consistent with basal cell carcinoma of nodular, adenoid and focal infiltrative type. The patient underwent Mohs micrographic surgery. After the first stage of Mohs micrographic surgery clear lateral surgical margins were achieved, however tumor was positive at the deep margin. After the second stage of Mohs surgery total tumor-free surgical margins were achieved with a defect size of $35 \times 30 \mathrm{~mm}$ at the junction of the three cosmetic units of the lower eyelid, infraorbital cheek and lateral side-wall of the nose (Figure 3). A repair paying attention to the cosmetic subnunits of the face resulted with a satisfactory appearance both for the patient and the operators (Figure 4-7).

Informed consent and permission for publication of patient's photos and medical data was taken from the patient.

\section{References}

1. Most S, Alsarraf R, Larrabee W: Outcomes of facial cosmetic procedures. Facial Plast Surg 2002;18:119-24.

2. Fattahi TT: An overview of facial aesthetic units. J Oral Maxillofac Surg 2003;61:1207-11.

3. Little $A C$, Jones $B C$, DeBruine LM: Facial attractiveness: Evolutionary based research. Philos Trans R Soc Lond B Biol Sci 2011;366:1638-59.

4. Hofer $\mathrm{SO}$, Mureau MA. Improving outcomes in aesthetic facial reconstruction. Clin Plast Surg 2009;36:345-54.

5. Russo F, Linares M, Iglesias ME, et al: Reconstruction techniques of choice for the facial cosmetic units. Actas Dermosifiliogr 2017;108:729-37.

6. Flowers FP, Goldsmith $\mathrm{CB}$, Steadmon M: Surgical anatomy of the head and neck dermatology. Bolognia J, Schaffer J, Cerroni L: Fourth edition. Elsevier, 2017;2429-30.

7. Tan SL, Brandt MG, Yeung JC, Doyle PC, Moore CC: The aesthetic unit principle of facial aging. JAMA Facial Plast Surg 2015;17:33-8. 